\title{
Establishment of In Vivo Brain Imaging Method in Conscious Mice
}

\author{
Hiroshi Mizuma ${ }^{1}$, Miho Shukuri ${ }^{1}$, Takuya Hayashi ${ }^{1}$, Yasuyoshi Watanabe ${ }^{2}$, and Hirotaka Onoe ${ }^{1}$ \\ ${ }^{1}$ Functional Probe Research Laboratory, RIKEN Center for Molecular Imaging Science, Kobe, Japan; and ${ }^{2}$ Molecular Probe \\ Dynamics Laboratory, RIKEN Center for Molecular Imaging Science, Kobe, Japan
}

In vivo imaging, such as PET, requires restriction of body movements and is generally conducted under sedation by anesthetic agents in studies using laboratory animals. Because anesthetics reduce neural activity and metabolism, physiologic neural functions are difficult to assess in animal PET studies. Therefore, use of an appropriate method in conscious animals is important and is a practical requirement for physiologic in vivo brain imaging studies. Here, we established an in vivo imaging system for conscious mice to reveal the physiologic regional cerebral glucose metabolic rate (rCMRglu) with ${ }^{18} \mathrm{~F}-\mathrm{FDG}$ PET. Methods: We first developed a head holder to enable brain PET of a conscious mouse. To obtain optimal rCMRglu, we examined the effects of physical and psychologic stresses caused by ambient temperature, intravenous injection, and acclimation to the apparatus and immobile state. Finally, quantitative kinetic analysis was performed for rCMRglu based on a 2-tissue-compartment model with an input function of arterial blood sampling under both conscious and anesthetized ( $1.5 \%$ isoflurane) conditions. Results: Increasing the ambient temperature increased uptake of ${ }^{18} \mathrm{~F}-\mathrm{FDG}$ in the brain significantly while reducing the uptake in skeletal muscle and brown adipose tissue that was caused by shivering. The reduction of brain ${ }^{18} \mathrm{~F}-\mathrm{FDG}$ uptake caused by tail holding and manual injection was significantly ameliorated by the use of an automated slow injection. Although brain uptake of ${ }^{18} \mathrm{~F}-\mathrm{FDG}$ varied at the first session of PET, uptake at the second and subsequent sessions was stable, even after long-term acclimation. After these beneficial changes, brain uptake of ${ }^{18}$ F-FDG improved significantly, to approximately $260 \%$ above the preconditioned state, which is comparable with that obtained in mice that have been allowed to move freely about their home cages. Quantitative kinetic analyses revealed that isoflurane anesthesia lowered rCMRglu in the cerebral cortex, striatum, thalamus, and cerebellum by $66 \%, 59 \%, 62 \%$, and $22 \%$, respectively, mainly by reducing the $k_{3}$ value, a rate constant for phosphorylation by hexokinase. Conclusion: To our knowledge, this is the first study to report quantitative kinetic analysis of rCMRglu in mice that have been conscious throughout PET. This investigation will open avenues for research into in vivo functional brain molecular imaging in both normal and genetically manipulated mice.

Received Jan. 18, 2010; revision accepted Mar. 16, 2010.

For correspondence or reprints contact: Hirotaka Onoe, Functional Probe Research Laboratory, RIKEN Center for Molecular Imaging Science (CMIS), 6-7-3 Minatojima-minami-machi, Chuo-ku, Kobe 6500047, Japan.

E-mail: hiro.onoe@riken.jp

COPYRIGHT @ 2010 by the Society of Nuclear Medicine, Inc.
Key Words: mouse; positron emission tomography (PET); consciousness; regional cerebral glucose metabolic rate (rCMRglu)

J Nucl Med 2010; 51:1068-1075

DOI: 10.2967/jnumed.110.075184

$\mathbf{R}$ ecent technologic advances in PET have enabled the study of brain imaging in mice, which has a significant advantage in the applicability of gene manipulation (1). Though cancer research is the main PET application for mice, it is also expected that mice can be used for PET studies of the intrinsic function of specific molecules modified by gene manipulation under in vivo physiologic conditions. Most in vivo molecular imaging studies, however, including PET, require restriction of the body and head to avoid motion artifacts while scanning. Artifacts constitute a serious problem for qualitative and quantitative image reconstructions $(2,3)$. Therefore, molecular imaging studies on laboratory animals are generally performed with the animals anesthetized to restrain voluntary body movements. Alterations in physiologic brain function, however, including a reduction in neural activities and brain metabolism, cannot be avoided in anesthetized animals (4). Hence, an in vivo neuroimaging technique that can be performed on conscious laboratory animals is required to investigate physiologic neural function in the same manner as for humans.

We previously established an experimental method for PET using conscious and trained macaque monkeys (5) and reported alterations in central neural transmission after the administration of anesthetics during PET. Significant reductions in brain glucose metabolism caused by inhalant and liquid anesthetics have also been found in rats, monkeys, and humans using the ${ }^{18} \mathrm{~F}-\mathrm{FDG}$ PET technique (6-8). Although changes in the brain distribution of ${ }^{18} \mathrm{~F}$ FDG by isoflurane and ketamine/xylazine anesthesia have been reported in mice $(9,10)$, little is known about the quantitative value of regional cerebral glucose use under the physiologic conscious state. In the present study, we developed a method for the quantitative kinetic analysis of in vivo brain PET performed on conscious mice, and we 
quantified regional cerebral glucose metabolic rate (rCMRglu) for, what is to our knowledge, the first time using a glucose analog ${ }^{18} \mathrm{~F}$-FDG PET technique.

\section{MATERIALS AND METHODS}

\section{Animal Preparation}

This study was performed in accordance with and approved by the Animal Care and Use Committee of RIKEN Kobe Institute (MAH18-02). Adult male C57BL/6J mice (8-10 wk old) were purchased from Clea Japan Inc. The mice were housed 4-5 to a cage, under a 12-h light-dark cycle (lights off at 8:00 PM) at $23^{\circ} \mathrm{C} \pm 1{ }^{\circ} \mathrm{C}$ and $60 \% \pm 5 \%$ humidity, and were allowed access to food and water ad libitum.

\section{Surgical Attachment of Head Holder}

To enable PET to be performed on conscious animals, an acrylic head holder (diameter, $6.0 \mathrm{~mm}$; height, $8.0 \mathrm{~mm}$ ) was surgically attached to the head of each mouse (Figs. 1A and 1B). At the time the head holder was attached, the mice were $12-16 \mathrm{wk}$ old and weighed $22-28 \mathrm{~g}$. Surgery was performed using a stereotactic apparatus (SR-6N; Narishige Co., Ltd.) under 1.5\% isoflurane anesthesia with $\mathrm{O}_{2}$ and $\mathrm{N}_{2} \mathrm{O}$ gases. The head holder was attached to the skull using an adhesive resin cement (Super-Bond C\&B; Sun Medical Co., Ltd.) that enabled tight fixation of the holder to the skull without any anchors. After attachment of the head holder, each mouse recovered from the surgery in its home cage for at least $1 \mathrm{wk}$ before PET. In addition, the mice were adequately acclimated to the head-holding system until the first PET experiment by being placed in the PET scanner for $2 \mathrm{~h}$ per day on alternate days at least 3 times, until they showed docile behavior (Fig. 1C).

\section{${ }^{18}$ F-FDG Preparation}

${ }^{18} \mathrm{~F}-\mathrm{FDG}$ was provided by the Division of Molecular Imaging at the Institute of Biomedical Research and Innovation. Briefly, ${ }^{18} \mathrm{~F}$ was produced by the nuclear reaction of ${ }^{18} \mathrm{O}(\mathrm{p}, \mathrm{n}){ }^{18} \mathrm{~F}$ using a cyclotron system (Cypris HM-18; Sumitomo Heavy Industries, Ltd.). According to the method of Füchtner et al. (11) with a minor modification, ${ }^{18} \mathrm{~F}-\mathrm{FDG}$ was automatically synthesized within 40 min using a radiochemical system (F-200; Sumitomo Heavy Industries, Ltd.).

\section{PET}

A catheter for ${ }^{18} \mathrm{~F}-\mathrm{FDG}$ injection was inserted into the tail vein, and $5 \mu \mathrm{L}$ of blood were collected to measure glucose levels before PET. With the head holder restricting movement, the mouse was placed on the bed of a small-animal PET scanner, the microPET Focus-220 (Siemens Medical Systems) (Fig. 1C). This scanner has a spatial resolution of $1.4 \mathrm{~mm}$ in full width at half maximum at the center of the field of view (220 $\mathrm{mm}$ in diameter) and an axial extent of $78 \mathrm{~mm}$ (12). Before the emission scan, the transmission scan was performed for $30 \mathrm{~min}$ using a ${ }^{68} \mathrm{Ge}-{ }^{68} \mathrm{Ga}$ pin source (18.5 MBq; Siemens Medical Systems) for attenuation correction. ${ }^{18} \mathrm{~F}-\mathrm{FDG}$ at a dose of $0.39-0.88 \mathrm{MBq} / \mathrm{g}$ of body weight dissolved in $0.1 \mathrm{~mL}$ of physiologic saline was automatically injected via the cannula inserted into the tail vein for $10 \mathrm{~s}$ using a syringe pump (PHD-2000; Harvard Apparatus Inc.), and emission data were then acquired for $60 \mathrm{~min}$ using a 3-dimensional list-mode method. These data were sorted into 45 frames $(10 \times 3 \mathrm{~s}, 3 \times 10 \mathrm{~s}, 6 \times 30 \mathrm{~s}$, $11 \times 60 \mathrm{~s}$, and $15 \times 180 \mathrm{~s}$ ).

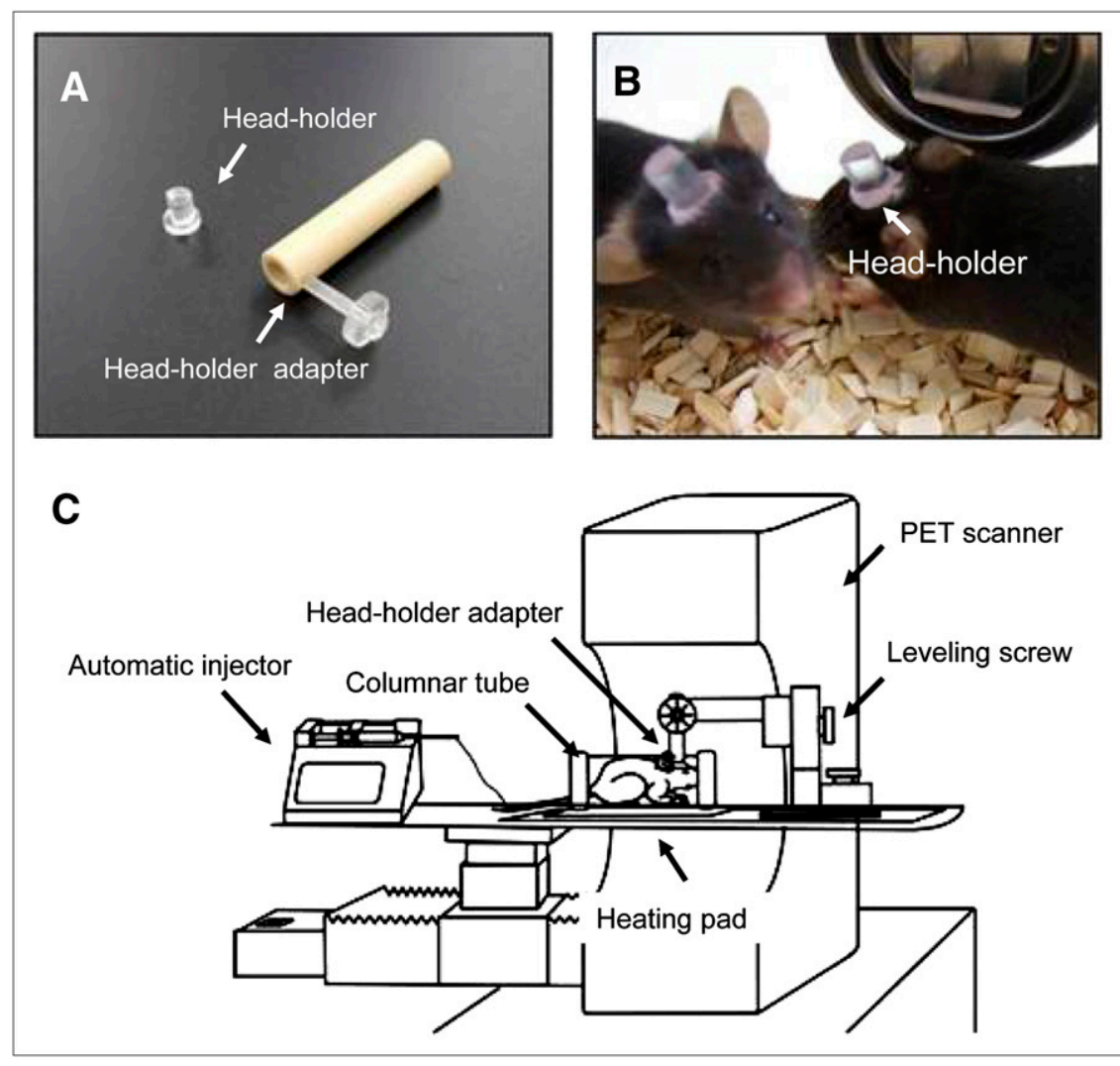

FIGURE 1. Photographs and schematic illustration of apparatus for brain PET of conscious mouse. ( $A$ and $B$ ) Convex acrylic head holder $(8 \mathrm{~mm}$ high, $6 \mathrm{~mm}$ in diameter) is surgically bonded to mouse's skull with dental resin. (C) Drawing shows how conscious mouse is held in PET system. 
The images were reconstructed using a filtered backprojection algorithm for quantitative evaluation of ${ }^{18}$ F-FDG uptake, by a maximum a posteriori algorithm for drawing regions of interest, with attenuation correction, no scatter correction, and smoothing by a gaussian kernel of $3 \mathrm{~mm}$ in full width at half maximum in all directions. Volumetric regions of interest were manually placed on several brain regions (cerebral cortex, striatum, thalamus, superior colliculus, pons/medulla, cerebellum, and locus ceruleus) according to the fused PET/MR T1-weighted images. The brain MR images were obtained using a 3-T MRI scanner (Signa Horizon Lx VH3; GE Healthcare) with a custom-made coil.

Quantitative analysis of ${ }^{18} \mathrm{~F}$-FDG uptake was performed using PMOD software (version 3.0; PMOD Technologies Ltd.). The index of ${ }^{18} \mathrm{~F}$-FDG uptake in brain tissues was shown as standardized uptake value (SUV): SUV = tissue radioactivity concentration $\left(\mathrm{MBq} / \mathrm{cm}^{3}\right) /$ injected radioactivity $(\mathrm{MBq}) \times$ body weight $(\mathrm{g})$. There was a tendency for the first ${ }^{18} \mathrm{~F}$-FDG PET scan to show a low SUV in all brain regions; therefore, multiple ${ }^{18}$ F-FDG PET scans were obtained, imaging data from the first scan were discarded, and data from the second or subsequent scans were used. Motion of the mouse brain on the PET images was quantitatively estimated using a software-based registration (Supplemental Methods [supplemental materials are available online only at http://jnm.snmjournals.org]), which showed that estimated translations in the $x$-, $y$-, and $z$-axis directions were less than \pm 1 $\mathrm{mm}$ on average and were considered to be within the spatial resolution of PET images (Supplemental Table 1; Supplemental Videos 1 and 2).

\section{Experimental Conditions of ${ }^{18}$ F-FDG PET in Conscious Mice}

To establish a method of measuring the physiologic state of a conscious mouse using this system, we first investigated the effects that body temperature and physical and psychologic stress during tracer injection have on brain ${ }^{18} \mathrm{~F}$-FDG uptake. Because the room temperature of the laboratory was set at $18^{\circ} \mathrm{C}$ to maintain the quality of the PET detector, the mouse was placed on a heating pad to maintain body temperature. To measure body temperature during PET, a rectal temperature probe (IT-18; ADInstruments, Inc.) was placed in each mouse. Rectal temperature was recorded with a temperature controller (CMA 150; CMA Microdialysis $\mathrm{AB})$ at 10-min intervals during the PET scan under warmed and unwarmed conditions.

For catheterization, a 30-gauge needle (BD) connected to a 30$\mathrm{cm}$ polyethylene tube (PE-10; $\mathrm{BD}$ ) was inserted into the tail vein (9), and ${ }^{18}$ F-FDG (19.0-19.7 MBq/0.1 mL) was injected via the catheter for $10 \mathrm{~s}$ using a syringe pump. In uncatheterized mice, intravenous injection of ${ }^{18} \mathrm{~F}-\mathrm{FDG}(19.2-20.8 \mathrm{MBq} / 0.1 \mathrm{~mL})$ was performed manually. To obtain precise and steady kinetics for input function, no saline flush was given after ${ }^{18} \mathrm{~F}-\mathrm{FDG}$ injection. Brain ${ }^{18} \mathrm{~F}$-FDG uptake was measured in mice that had been moving freely in their home cage for 30 min after manual ${ }^{18} \mathrm{~F}$ FDG injection and were subsequently scanned for 30 min under $1.5 \%$ isoflurane anesthesia. The blood glucose concentration was carefully monitored and the feeding period controlled to maintain normoglycemia at the beginning of PET.

\section{Serum Corticosterone Level}

To monitor the stress caused by fixation of the head during PET in conscious mice, serum corticosterone levels were measured $1 \mathrm{~h}$ after head fixation at each time point at 1, 3, 13, and $30 \mathrm{~d}$ after the start of acclimation. Blood samples for serum corticosterone measurements were collected from the left ventricle of individual mice in each condition under $3 \%$ isoflurane anesthesia. The aliquot was centrifuged at $1,500 \mathrm{~g}$ at $4^{\circ} \mathrm{C}$ for $10 \mathrm{~min}$ to prepare serum, which was stored at $-20^{\circ} \mathrm{C}$ until assay. The serum corticosterone level was measured using a ${ }^{125} \mathrm{I}$-rCorticosterone radioimmunoassay kit (Institute of Isotopes Co., Ltd.).

\section{Glucose Kinetics}

To measure rCMRglu as an index of quantitative glucose use in the brain, blood was collected from the femoral artery during PET. Arterial blood sampling was performed according to a previously reported method, with some modifications (13). A 20-cm polyethylene catheter (PE-10; BD) was inserted into the femoral artery under $1.5 \%$ isoflurane anesthesia, and each mouse was then allowed to recover from anesthesia in an acrylic cage for more than $3 \mathrm{~h}$ until the PET scan. Arterial blood sampling was performed concurrently with ${ }^{18}$ F-FDG PET; 25 samples were collected using a $0.5-\mu \mathrm{L}$ capillary tube (Drummond Scientific Co.) at intervals of $3 \mathrm{~s}$ from 0 to $60 \mathrm{~s}$, and at 2, 5, 10, 30, and 60 min after injection of ${ }^{18} \mathrm{~F}-\mathrm{FDG}$, from the initiation of PET in both conscious mice and mice under $1.5 \%$ isoflurane anesthesia.

The ${ }^{18} \mathrm{~F}$ radioactivity of each sample was measured using a $\gamma$-well counter (Wizard 1480; PerkinElmer Inc.). Cerebral ${ }^{18}$ F-FDG kinetics were analyzed by 3-compartment modeling using the blood glucose concentration and the ${ }^{18} \mathrm{~F}$ radioactivities of brain tissue obtained from dynamic PET images and arterial blood samples-the so-called input function $(14,15)$. A 3-compartment model was used in analyses of rCMRglu $(\mu \mathrm{mol} / \mathrm{min} / 100 \mathrm{~g})$. The ${ }^{18} \mathrm{~F}-\mathrm{FDG}$ rate constants $K_{1}(\mathrm{~mL} / \mathrm{min} / \mathrm{g})$ and $k_{2}\left(\mathrm{~min}^{-1}\right)$ were expressed as intra- and extracellular transportation, respectively, mediated by glucose transporters across cytomembranes, and $k_{3}$ $\left(\min ^{-1}\right)$ and $k_{4}\left(\min ^{-1}\right)$ represent phosphorylation by hexokinase and dephosphorylation by glucose-6-phosphatase, respectively. A lumped constant of 0.625 was used, as previously described (16).

\section{Ex Vivo Brain Slice Autoradiography}

To assess the quantification of emission data, ex vivo brain slice autoradiography was performed (17). After the PET scan, mice were sacrificed under deep anesthesia with $3.0 \%$ isoflurane and the brain was sliced into coronal sections (1 mm thick) using a brain matrix (RBM-2000C; ASI instruments) in a cold room. The coronal slices were placed on an imaging plate (BASSR2040; Fuji Photo Film) for $20 \mathrm{~min}$. The exposed imaging plate was then scanned by a bioimaging analyzer (FLA-7000IR; Fuji Photo Film). To obtain quantitative data from ex vivo autoradiograms, regions of interest were manually placed on several brain regions (e.g., cerebral cortex, striatum, thalamus, superior colliculus, pons, cerebellum, and locus ceruleus) according to the digital photograph obtained from a photo scanner. The radioactivity level in the brain slices was expressed as photostimulated luminescence per area $\left(\mathrm{mm}^{2}\right) /$ injected radioactivity $(\mathrm{MBq}) \times$ body weight $(\mathrm{kg})$.

\section{Statistical Analyses}

All data are presented as mean and SEM. Body temperature, corticosterone level, and glucose kinetics were compared using an unpaired Student $t$ test. Changes in ${ }^{18} \mathrm{~F}$-FDG uptake by warming or by cannulating, and changes in the corticosterone level, were subjected to 1-way ANOVA followed by the postvariance TukeyKramer honestly significant difference test. Correlation of ${ }^{18} \mathrm{~F}-\mathrm{FDG}$ uptake between PET and ex vivo autoradiography was evaluated by 


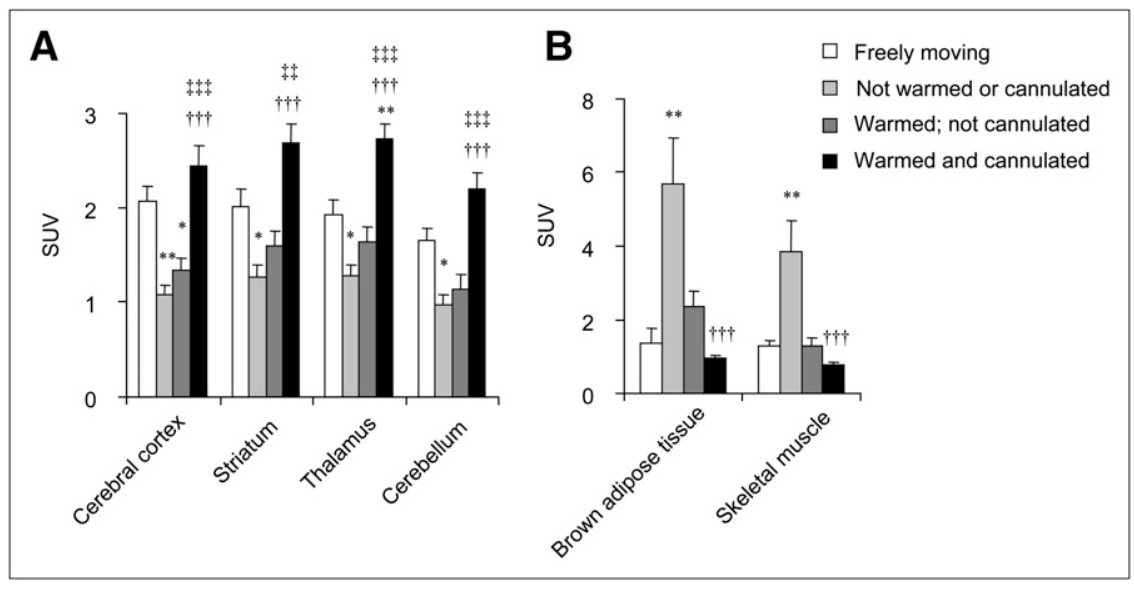

FIGURE 2. SUVs for brain regions (A) and for brown adipose tissue and skeletal muscle (B). Error bar is SEM $(n=5)$. ${ }^{\star} P<0.05,{ }^{\star \star} P<0.01$, vs. freely moving condition. ${ }^{\dagger \dagger} P<0.01$, ${ }^{\dagger+t} P<$ 0.001 , vs. not warmed and not cannulated conditions. $¥ \neq P<0.01, \neq \neq \ddagger P<$ 0.001 , vs. warmed and not cannulated conditions.

the Pearson linear correlation coefficient. A probability level of less than 0.05 was considered statistically significant.

\section{RESULTS}

Effect of Experimental Conditions on ${ }^{18}$ F-FDG Uptake in Conscious Mice

Regional brain ${ }^{18}$ F-FDG uptake under the warmed condition was $20 \%$ higher than that under the unwarmed condition, whereas ${ }^{18} \mathrm{~F}$-FDG uptake in brown adipose tissue and skeletal muscle under the warmed condition was $60 \%$ lower than that under the unwarmed condition (Fig. 2; Supplemental Figs. 1B and 1C). Although a small increase in rectal temperature was observed at the beginning of the PET experiment under both the warmed $\left(38.6^{\circ} \mathrm{C} \pm 0.1^{\circ} \mathrm{C}\right)$ and the unwarmed $\left(38.6^{\circ} \mathrm{C} \pm 0.1^{\circ} \mathrm{C}\right)$ conditions, compared with the basal rectal temperature in mice that were allowed to move freely about their home cage $\left(37.2^{\circ} \mathrm{C} \pm 0.2^{\circ} \mathrm{C}\right)$, a gradual decrease in temperature was observed only under the warmed condition as scanning progressed (Supplemental Fig. 2).

Automated slow injection with a syringe pump through a prepared indwelling venous catheter caused $80 \%$ higher and $60 \%$ lower uptake of ${ }^{18}$ F-FDG by the brain and brown adipose tissue, respectively, compared with uptake after general manual intravenous injection (Fig. 2; Supplemental Figs. $1 \mathrm{C}$ and 1D). The SUVs of ${ }^{18}$ F-FDG in the brain obtained with warming and automated slow injection showed a high value overall compared with those of the freely moving mice; in particular, SUV was significantly high in the thalamus $(P<0.01)$ (Fig. 2A; Supplemental Figs. 1A and 1D).

Under the conscious condition, because the brain ${ }^{18} \mathrm{~F}$ FDG uptake obtained at the first PET scan varied, PET scans were performed several times in the same individual to acclimate the mouse to the apparatus and PET procedure. No significant difference was found in regional ${ }^{18} \mathrm{~F}-\mathrm{FDG}$ uptake between 3 and $28 \mathrm{~d}$ of acclimation. Thus, regional brain ${ }^{18} \mathrm{~F}$-FDG uptake was consistent and stable between 3 and $28 \mathrm{~d}$ of acclimation (Supplemental Fig. 3A). Despite this lengthy acclimation to the head holder, serum glucose levels showed no significant change (data not shown), whereas serum corticosterone levels did not regain the levels found in intact mice housed in their home cage (Supplemental Fig. 3B).

\section{Comparison of Glucose Kinetics Between Conscious and Anesthetized Conditions}

We performed PET with ${ }^{18} \mathrm{~F}-\mathrm{FDG}$ for $60 \mathrm{~min}$ using this method, and we compared rCMRglu in both conscious and anesthetized mice. Under the $1.5 \%$ isoflurane-anesthetized condition, brain ${ }^{18} \mathrm{~F}$-FDG uptake was totally and markedly decreased in all brain regions, compared with that under the conscious condition (Fig. 3). In conscious mice, timeactivity curves for the thalamus and cerebellum showed a progressive increase in ${ }^{18} \mathrm{~F}$-FDG uptake until the maximum level was reached at $30 \mathrm{~min}$ after injection (Fig. 4A). In contrast, under $1.5 \%$ isoflurane anesthesia, ${ }^{18} \mathrm{~F}-\mathrm{FDG}$

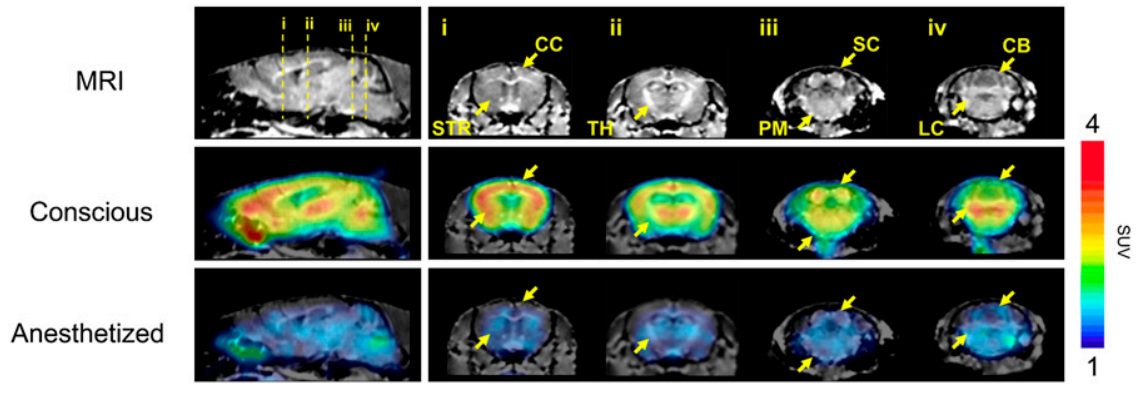

FIGURE 3. ${ }^{18} \mathrm{~F}-\mathrm{FDG}$ PET/MR fused images of mouse brain under conscious and $1.5 \%$ isoflurane-anesthetized conditions. Yellow dashed lines (i-iv) on sagittal MR image indicate position of coronal MR images. Brain regions are indicated by yellow arrows. $\mathrm{CB}=$ cerebellum; CC = cerebral cortex; $\mathrm{LC}=$ locus ceruleus; $\mathrm{PM}=$ pons/medulla; $\mathrm{SC}=$ superior colliculus; STR $=$ striatum; $\mathrm{TH}=$ thalamus. 


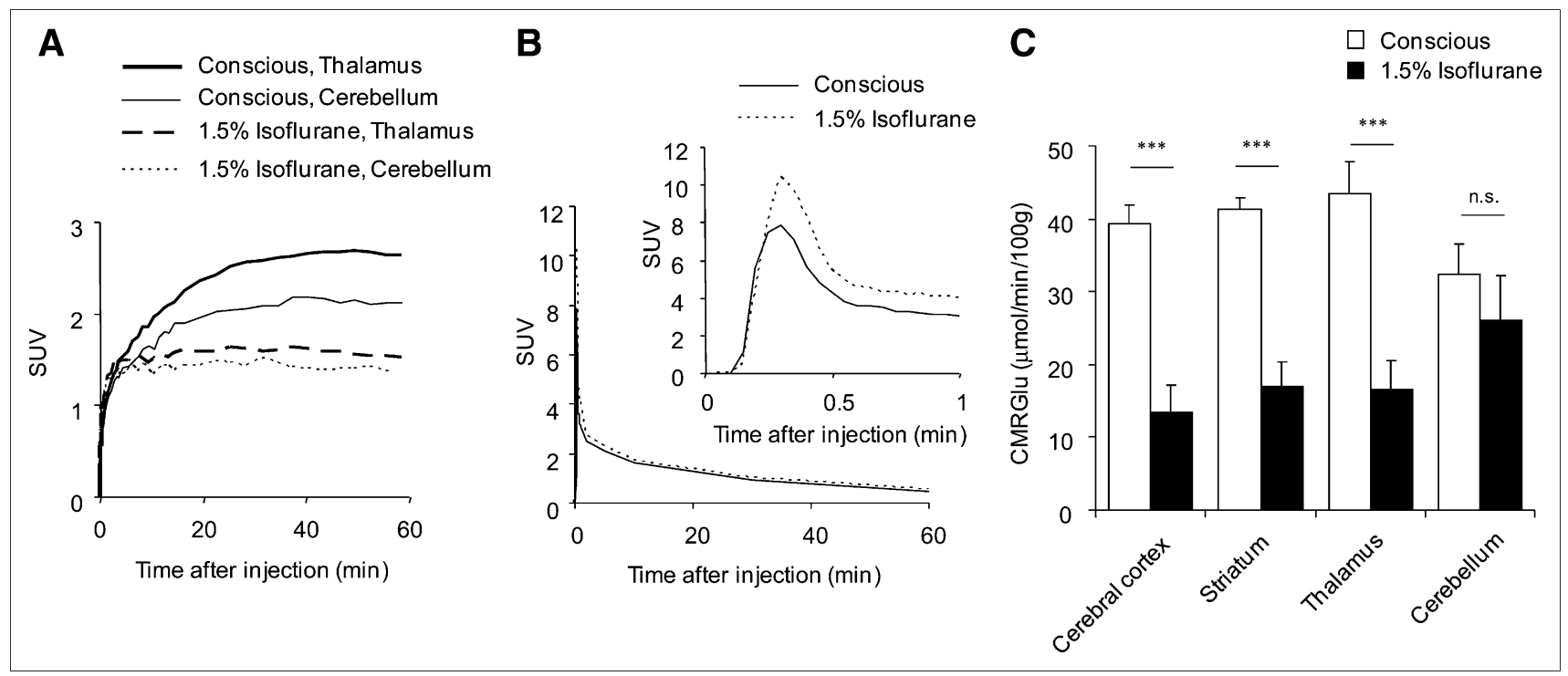

FIGURE 4. (A) Mean time-radioactivity curves are shown for thalamus and cerebellum after injection of ${ }^{18} \mathrm{~F}-\mathrm{FDG}$ in conscious and $1.5 \%$ isoflurane-anesthetized mice $(n=4)$. (B) Changes in ${ }^{18} \mathrm{~F}$ radioactivity of serial arterial blood samples in mice. (C) rCMRglu is shown for various brain regions, as estimated by glucose kinetic analysis. Error bar is SEM $(n=4)$. ${ }^{\star \star \star} P<0.001$ vs. conscious condition.

uptake showed immediate elevation and plateaued within 2 min after injection (Fig. 4A). The coronal ${ }^{18} \mathrm{~F}$-FDG brain images measured by PET and ex vivo autoradiography showed clear and well-correlated regional uptake of ${ }^{18} \mathrm{~F}-$ FDG for both methods $\left(R^{2}=0.89, P<0.001\right)$ (Fig. 5). Therefore, the qualitative and quantitative validities of the acquired PET images were similar to those of ex vivo autoradiography.

rCMRglu, as calculated from radioactivity data of both brain PET and arterial blood (Fig. 4B), was 66\%, 59\%, $60 \%$, and $22 \%$ lower in the cerebral cortex, striatum, thalamus, and cerebellum, respectively, with $1.5 \%$ isoflurane than with no anesthesia. This result strongly indicates the functionality of the brain in sustaining awareness (Fig. 4C). The $k_{3}$ value of all brain regions examined was $32 \%-78 \%$ lower in anesthetized mice than in conscious mice (Table 1); $K_{1}$ and $k_{2}$ values differed only in the thalamus between conscious and anesthetized mice (Table 1).

\section{DISCUSSION}

\section{Effects of Warming and Venous Catheterization on Cerebral ${ }^{18}$ F-FDG Uptake}

We first tested the effects of the 3 experimental conditions - warming, catheterization, and acclimation-on brain ${ }^{18} \mathrm{~F}-\mathrm{FDG}$ uptake using PET in conscious mice. After
FIGURE 5. Comparison of brain PET with ex vivo slice autoradiography in ${ }^{18} \mathrm{~F}-\mathrm{FDG}$ mouse studies. (A) Regional distribution of ${ }^{18} \mathrm{~F}-\mathrm{FDG}$ uptake in coronal PET images, summed for $30 \mathrm{~min}$ (30-60 min after injection and overlaid on MR images), corresponded well with that in coronal brain slices $(1-\mathrm{mm}$ thickness) in ex vivo autoradiograms (ARG), exposed 30 min after PET and overlaid on digital photographs. Images were obtained under conscious and $1.5 \%$ isoflurane-anesthetized conditions. (B) Positive and significant correlation was observed between PET and ex vivo autoradiography for regional brain ${ }^{18} \mathrm{~F}-\mathrm{FDG}$ uptake. Data points represent values for 7 brain regions; circles and crosses represent conscious and $1.5 \%$ isoflurane-anesthetized conditions, respectively $(n=5)$. PSL $=$ photostimulable luminescence.
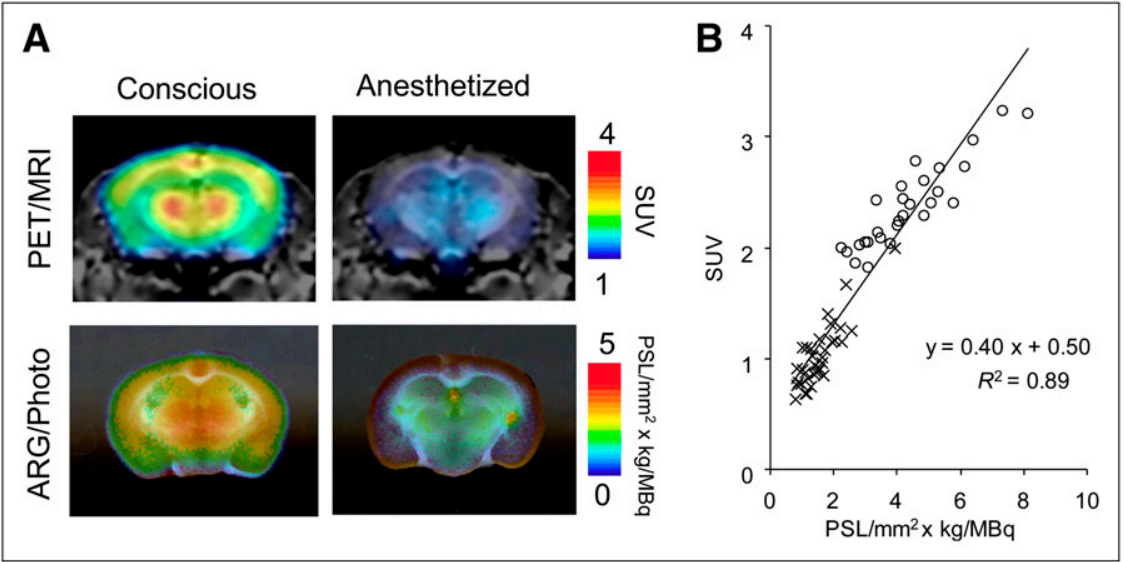


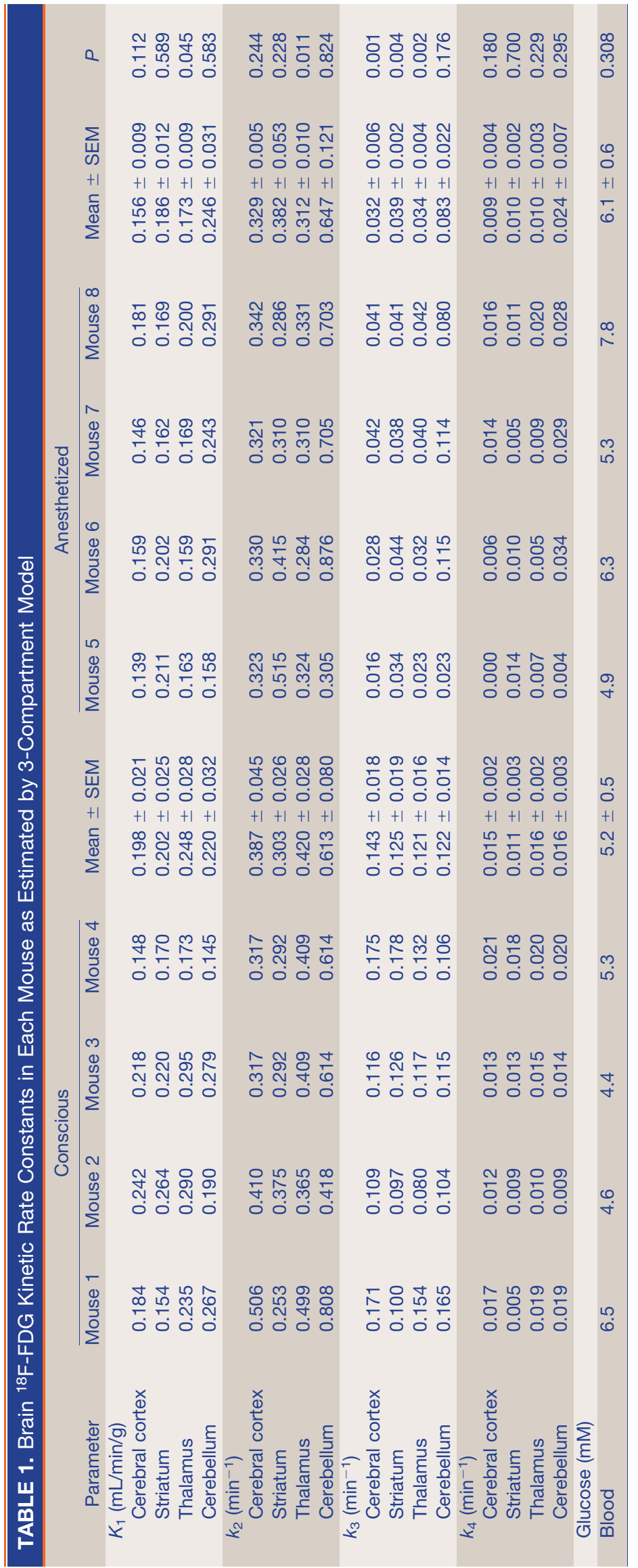


warming of the mice using a body temperature controller during PET, ${ }^{18}$ F-FDG uptake showed a slight increase in the brain and significant decreases in the skeletal muscle and brown adipose tissue, compared with uptake in unwarmed mice. Haman et al. reported that low-intensity shivering for heat production is related to an increase in plasma glucose and muscular glycogen (18), and ${ }^{18} \mathrm{~F}-\mathrm{FDG}$ PET studies in humans revealed that cerebral glucose uptake decreases globally with increasing exercise intensity $(19,20)$.

The small increase in rectal temperature observed at the beginning of the PET experiment under both the warmed and the unwarmed conditions may have occurred because of emotional hyperthermia (21) derived from the physiologic and mental stresses induced by head fixation and insertion of the rectal probe in conscious mice. In addition, in unwarmed mice, this elevated body temperature was maintained during PET because of thermogenesis by shivering for protection against environmental stress caused by the low room temperature. In contrast, because warmed mice were free from environmental stress, rectal temperatures of the mice were gradually decreased. Taken together, these results indicate that the high ${ }^{18} \mathrm{~F}-\mathrm{FDG}$ uptake in brown adipose tissue and skeletal muscle in unwarmed mice may be related to shivering to maintain body temperature.

In the present study, brain ${ }^{18} \mathrm{~F}$-FDG uptake was dramatically increased in mice that received automatic injection via an indwelling catheter in the tail vein. In conscious mice, injection of approximately $20 \mathrm{MBq}$ with a volume of $0.1 \mathrm{~mL}$ or less is required for appropriate ${ }^{18} \mathrm{~F}-\mathrm{FDG}$ PET and would be technically difficult to achieve by manual injection. In addition, manual intravenous injection causes stress when the tail is gripped during injection. Because these physical and mental stresses may produce low brain and high brown adipose tissue uptake of ${ }^{18} \mathrm{~F}-\mathrm{FDG}$ in conscious mice, it is important to perform catheterization and automatic slow and continuous injection with a syringe pump. The level of brain ${ }^{18}$ F-FDG uptake obtained in warmed mice with automated slow injection at 30-60 min after ${ }^{18}$ F-FDG injection was similar to that of mice moving freely in the home cage for $30 \mathrm{~min}$ after ${ }^{18} \mathrm{~F}$-FDG injection.

A previous study that investigated the relationship between glucose kinetics and stress response reported that the stress induced by sham intraperitoneal injections caused a slight increase in plasma glucose but no change in brain glucose (22). In humans, a significant negative correlation between rostral medial prefrontal cortical ${ }^{18} \mathrm{~F}-\mathrm{FDG}$ uptake and salivary cortisol was observed by psychosocial stress exposure (23). In contrast, a ${ }^{14} \mathrm{C}$-labeled 2-deoxyglucose autoradiographic study showed increased regional cerebral glucose use in rats stressed by immobilization (6). Taking these reports into account, brain uptake of ${ }^{18} \mathrm{~F}-\mathrm{FDG}$ could be affected by ambient stress, although the nature of this relationship varies among different studies, possibly because of differences in strain and stress. In our study of mice, a significant gradual decrease in serum corticosterone concentration was observed during the acclimation period, indicating the attenuation of stress response, though the level was still significantly higher than that of the intact mice. However, ${ }^{18} \mathrm{~F}-\mathrm{FDG}$ uptake in the brain was not significantly different between day 3 and day 28 of acclimation, suggesting that from the viewpoint of brain ${ }^{18} \mathrm{~F}$-FDG uptake, global brain activity is not closely related to serum corticosterone level.

\section{Comparison of Glucose Kinetics Between Conscious and Anesthetized Conditions}

We used SUV and rCMRglu as indices of glucose use in the mouse brain. Although PET images of SUV are useful because they represent the relative glucose uptake and distribution in the brain without invasive arterial blood sampling, the absolute SUV does not necessarily reflect actual neural activity-dependent glucose metabolism. As shown in the present study, blood glucose concentration and physiologic conditions affected the SUVs of ${ }^{18} \mathrm{~F}-\mathrm{FDG}$ under anesthesia. In contrast, evaluation of glucose use by 3-compartment modeling with arterial blood sampling is known to represent the precise rCMRglu with components of glucose transporting $\left(K_{1}\right)$ and phosphorylation $\left(k_{3}\right)$. Our results show that, compared with conscious mice, mice anesthetized with $1.5 \%$ isoflurane had dramatically lower rCMRglu in all brain regions except the cerebellum because of a reduced $k_{3}$ value but unaffected $K_{1}$ value.

These results were consistent with a previous human ${ }^{18} \mathrm{~F}$ FDG PET study that compared the conscious and anesthetized conditions: Alkire et al. reported that global rCMRglu was $46 \%$ lower under isoflurane-induced anesthesia than in the conscious state (8). Isoflurane is an inhalant anesthetic commonly used in ${ }^{18} \mathrm{~F}-\mathrm{FDG}$ PET studies of laboratory animals. Isoflurane anesthesia has been reported to affect blood glucose levels (24), cerebral blood flow (25), and rCMRglu (26) in rodents. In addition, isoflurane anesthesia causes high myocardial ${ }^{18} \mathrm{~F}-\mathrm{FDG}$ uptake in mice (9). Therefore, isoflurane profoundly influences glucose use in both central and peripheral organs. The rCMRglu values obtained in mice anesthetized by isoflurane in the present study are consistent with those reported by previous studies that estimated these values using ${ }^{18} \mathrm{~F}$-FDG PET in mice (13,27). In addition, previous rat studies with ${ }^{18} \mathrm{~F}-\mathrm{FDG}$ showed that rCMRglu was decreased by $30 \%-75 \%$ with isoflurane anesthesia, compared with the values in conscious rats $(28,29)$. Thus, because the rCMRglu levels obtained in the present study in conscious mice were almost 2 times higher than those in anesthetized mice, these results strongly indicate that our method is more appropriate than the conventional method for assessing physiologic rCMRglu in conscious mice.

PET neuroimaging of conscious mice is applicable to various types of genetically manipulated mice. We recently succeeded in using this method to demonstrate in vivo dysfunction of glucose transporters in a glucose transporter 
type 1 gene-modified mouse, which is considered to be a human disease model of glucose transporter type 1 deficit syndrome. Interestingly, this functionality was observed only under the conscious condition.

\section{CONCLUSION}

We developed an in vivo molecular imaging system for conscious mice; the method is applicable to measuring rCMRglu using the kinetic compartment model. In the present study, we established an in vivo brain imaging technique in conscious mice and elucidated, for what is to our knowledge the first time, rCMRglu by 2-tissue-compartment kinetic modeling $\left(K_{1}\right.$ and $k_{2}$ for glucose transport; $k_{3}$ and $k_{4}$ for phosphorylation and dephosphorylation). We also revealed that the decrease in rCMRglu caused by isoflurane anesthesia was induced by a reduction of $k_{3}$ in the brain. In vivo neuroimaging of conscious mice has significant advantages in terms of its applicability to genetically manipulated mice as models of human disease.

\section{ACKNOWLEDGMENTS}

We thank Keiko Tokuda, Chiho Takeda, Chiyuki Kuriyama, Emi Hayashinaka, and Yasuhiro Wada for their technical assistance, and we thank Drs. Kazuhiro Takahashi and Masahiro Sasaki for providing ${ }^{18}$ F-FDG. This study was supported by the Molecular Imaging Research Program from the Ministry of Education, Culture, Sports, Science and Technology of the Japanese Government.

\section{REFERENCES}

1. Beckmann N, Kneuer R, Gremlich HU, Karmouty-Quintana H, Ble FX, Muller M. In vivo mouse imaging and spectroscopy in drug discovery. NMR Biomed. 2007;20:154-185.

2. Buhler P, Just U, Will E, Kotzerke J, van den Hoff J. An accurate method for correction of head movement in PET. IEEE Trans Med Imaging. 2004;23:1176-1185.

3. Herzog H, Tellmann L, Fulton R, et al. Motion artifact reduction on parametric PET images of neuroreceptor binding. J Nucl Med. 2005;46:1059-1065.

4. Franks NP. General anaesthesia: from molecular targets to neuronal pathways of sleep and arousal. Nat Rev Neurosci. 2008;9:370-386.

5. Onoe $\mathrm{H}$, Inoue $\mathrm{O}$, Suzuki $\mathrm{K}$, et al. Ketamine increases the striatal $\mathrm{N}-\left[{ }^{11} \mathrm{C}\right]$ methylspiperone binding in vivo: positron emission tomography study using conscious rhesus monkey. Brain Res. 1994;663:191-198.

6. Bryan RM Jr, Hawkins RA, Mans AM, Davis DW, Page RB. Cerebral glucose utilization in awake unstressed rats. Am J Physiol. 1983;244:C270-C275.

7. Moore AH, Cherry SR, Pollack DB, Hovda DA, Phelps ME. Application of positron emission tomography to determine cerebral glucose utilization in conscious infant monkeys. J Neurosci Methods. 1999;88:123-133.

8. Alkire MT, Haier RJ, Shah NK, Anderson CT. Positron emission tomography study of regional cerebral metabolism in humans during isoflurane anesthesia. Anesthesiology. 1997;86:549-557.

9. Toyama H, Ichise M, Liow JS, et al. Evaluation of anesthesia effects on $\left[{ }^{18} \mathrm{~F}\right] \mathrm{FDG}$ uptake in mouse brain and heart using small animal PET. Nucl Med Biol. 2004;31:251-256.
10. Fueger BJ, Czernin J, Hildebrandt I, et al. Impact of animal handling on the results of ${ }^{18}$ F-FDG PET studies in mice. $J$ Nucl Med. 2006;47:999-1006.

11. Füchtner F, Steinbach J, Mäing P, Johannsen B. Basic hydrolysis of 2$\left[{ }^{18} \mathrm{~F}\right]$ fluoro-1,3,4,6-tetra-O-acetyl-D-glucose in the preparation of 2 - $\left[{ }^{18} \mathrm{~F}\right]$ fluoro2-deoxy-glucose. Appl Radiat Isot. 1996;47:61-66.

12. Tai YC, Ruangma A, Rowland D, et al. Performance evaluation of the microPET focus: a third-generation microPET scanner dedicated to animal imaging. $\mathrm{J} \mathrm{Nucl}$ Med. 2005;46:455-463.

13. Toyama H, Ichise M, Liow JS, et al. Absolute quantification of regional cerebral glucose utilization in mice by ${ }^{18} \mathrm{~F}$-FDG small animal PET scanning and 2-14C-DG autoradiography. J Nucl Med. 2004;45:1398-1405.

14. Sokoloff L, Reivich M, Kennedy $\mathrm{C}$, et al. The $\left[{ }^{14} \mathrm{C}\right]$ deoxyglucose method for the measurement of local cerebral glucose utilization: theory, procedure, and normal values in the conscious and anesthetized albino rat. J Neurochem. 1977;28:897916.

15. Phelps ME, Huang SC, Hoffman EJ, Selin C, Sokoloff L, Kuhl DE. Tomographic measurement of local cerebral glucose metabolic rate in humans with (F-18)2-fluoro-2-deoxy-D-glucose: validation of method. Ann Neurol. 1979;6:371-388.

16. Moore AH, Osteen CL, Chatziioannou AF, Hovda DA, Cherry SR. Quantitative assessment of longitudinal metabolic changes in vivo after traumatic brain injury in the adult rat using FDG-microPET. J Cereb Blood Flow Metab. 2000;20: 1492-1501.

17. Matsumura A, Mizokawa S, Tanaka M, et al. Assessment of microPET performance in analyzing the rat brain under different types of anesthesia: comparison between quantitative data obtained with microPET and ex vivo autoradiography. Neuroimage. 2003;20:2040-2050.

18. Haman F, Peronnet F, Kenny GP, et al. Effect of cold exposure on fuel utilization in humans: plasma glucose, muscle glycogen, and lipids. J Appl Physiol. 2002; 93:77-84.

19. Kemppainen J, Aalto S, Fujimoto T, et al. High intensity exercise decreases global brain glucose uptake in humans. J Physiol. 2005;568:323-332.

20. Tashiro M, Itoh M, Fujimoto T, Masud MM, Watanuki S, Yanai K. Application of positron emission tomography to neuroimaging in sports sciences. Methods. 2008;45:300-306.

21. Zethof TJ, Van der Heyden JA, Tolboom JT, Olivier B. Stress-induced hyperthermia in mice: a methodological study. Physiol Behav. 1994;55:109-115.

22. Thurston JH, Hauhart RE. Effect of momentary stress on brain energy metabolism in weanling mice: apparent use of lactate as cerebral metabolic fuel concomitant with a decrease in brain glucose utilization. Metab Brain Dis. 1989;4:177-186.

23. Kern S, Oakes TR, Stone CK, McAuliff EM, Kirschbaum C, Davidson RJ. Glucose metabolic changes in the prefrontal cortex are associated with HPA axis response to a psychosocial stressor. Psychoneuroendocrinology. 2008;33:517529.

24. Flores JE, McFarland LM, Vanderbilt A, Ogasawara AK, Williams SP. The effects of anesthetic agent and carrier gas on blood glucose and tissue uptake in mice undergoing dynamic FDG-PET imaging: sevoflurane and isoflurane compared in air and in oxygen. Mol Imaging Biol. 2008;10:192-200.

25. Lenz C, Rebel A, van Ackern K, Kuschinsky W, Waschke KF. Local cerebral blood flow, local cerebral glucose utilization, and flow-metabolism coupling during sevoflurane versus isoflurane anesthesia in rats. Anesthesiology. 1998;89: 1480-1488.

26. Ori C, Dam M, Pizzolato G, Battistin L, Giron G. Effects of isoflurane anesthesia on local cerebral glucose utilization in the rat. Anesthesiology. 1986;65: $152-156$.

27. Wu HM, Sui G, Lee CC, et al. In vivo quantitation of glucose metabolism in mice using small-animal PET and a microfluidic device. J Nucl Med. 2007;48: 837-845.

28. Maekawa T, Tommasino C, Shapiro HM, Keifer-Goodman J, Kohlenberger RW. Local cerebral blood flow and glucose utilization during isoflurane anesthesia in the rat. Anesthesiology. 1986;65:144-151.

29. Shimoji K, Ravasi L, Schmidt K, et al. Measurement of cerebral glucose metabolic rates in the anesthetized rat by dynamic scanning with ${ }^{18} \mathrm{~F}-\mathrm{FDG}$, the ATLAS small animal PET scanner, and arterial blood sampling. J Nucl Med. 2004;45:665-672. 